\title{
The Here and Hereafter of Myanmar Telecommunications Sector $^{1 *}$
}

\author{
Seong-Min Cha \\ Dept. of Law, Hannam University \\ 70 Hannam-Ro, Daeduk-Gu, Daejeon, KOREA \\ smcha@hnu.kr
}

\begin{abstract}
With Myanmar's open-door policy politically and economically, its telecommunications sector environments have been also changed rapidly. Former ICT legal system which is behind the times disappears little by little and, new ICT legal system which is in step with global trends has been established. An example is the enactment of telecommunications law 2013. In this paper, some implications of Myanmar telecommunications law and policy will be reviewed after analyzing current Myanmar telecommunications market. And then, I try to predict the near future of Myanmar telecommunications sector.
\end{abstract}

Keywords: Myanmar Telecommunications Law, Myanmar Telecommunications Market, Myanmar Telecommunications Policy, Competition Policy, Access Policy

\section{Introduction}

\subsection{Myanmar Legal System}

The development of Information and Communications Technology (ICT) has made great strides in every area of our society over the past decade. ICT became an essential element in human life. Technologically advanced countries have gained competitive edge over less-advanced countries in the areas of human endeavor.

Myanmar had its own legal system under the age of Myanmar kingdom. After having lost her independence, traditional legal system was repealed. Common law system which was modified in India was introduced by the British. Although Myanmar recovered her independence in 1948, the legal system had remained unaltered until 1962. From 1962 to 1988, Myanmar adopted the socialistic legal system. Since the age of the State Law and Order Restoration Council in 1988, Myanmar adopted the modified common law legal system which was similar to marginal states[1].

Myanmar has joined with e-ASEAN Framework Agreement which was adopted on 24th November, 2002. She has to abide by provisions in the e-ASEAN Framework Agreement. Article 5 of the Agreement says "Member States shall expeditiously put in place national laws and policies relating to electronic commerce transactions based on international norms".

Legal and regulatory framework plays a vital role to promote and to develop ICT sector. The legal framework concentrates not only on the current status but also future steps and long term policies. To develop of ICT sector and society, Myanmar enacted Telecommunications Law in 2013.

The ICT sector in Myanmar is undergoing dynamic change due to the political and economic reforms and foreign investment. Not that long ago, the Myanmar Posts and

\footnotetext{
* This work was supported by the National Research Foundation of Korea Grant funded by the Korean Government (NRF-2014S1A2A1A01027339)
} 
Telecommunications (MPT) which is a governmental agency was the only provider of telecommunication services in Myanmar. It is operating under the Ministry of Communications, Posts and Telegraphs. The Myanmar government however deregulated the telecommunications industry and permitted operating licenses to foreign companies: Telenor from Norway and Ooredoo from Qatar in 2013[2].

The new telecommunications law was signed into effect on October 8th 2013. The law says the framework for the telecommunication sector in Myanmar and repeals the obsolete Myanmar Telegraph Act, 1885 and the Myanmar Wireless Telegraph Act, 1934. New ICT laws which are highly advanced and have never been promulgated in Myanmar have the various legal perceptions[3].

\subsection{Former ICT Laws in Myanmar}

Main ICT laws were four in the old days; The Myanmar Telegraph Act 1885; The Myanmar Wireless Telegraphy Act 1934; The Computer Science Development Law 1996; The Electronic Transactions Law 2004.

The objectives of the Computer Science Development Law are to contribute towards the emergence of a modern developed State through computer science; to lay down and implement measures of computer science and technology; to cause extensively development in the use of computer science in the respective fields of works; and to supervise the import and export of computer software of information. The Computer Science Development Law consists of Objectives, Formation of the Myanmar computer Science Development Council, Duties and Powers of the Council, Formation of Computer Associations, Formation of the Federation, Duties and Powers of the Federation Finance, Prior Sanction and License, Offences and Penalties, and Miscellaneous.

The aims of the Electronic Transactions Law are to support with electronic transactions technology in building a modern and developed nation; to obtain more opportunities for all round development of sectors by electronic transactions technology; to recognize the authenticity and integrity of electronic record and electronic data message and give legal protection thereof; to enable transmitting, receiving and storing local and foreign information simultaneously; to enable communicating and co-operating effectively and speedily. The Electronic Transactions Law covers: Title and Definition, Aims, Applications, Formation of the Central Body of Electronic Transactions Control Board and Functions and Powers thereof, Certification Authority, Subscriber, Electronic Record, Electronic Data Message and Electronic Signature, Contracts made by Electronic Technology, Taking Administrative Action, Application for Revision Appeal, Offences and Penalties, and Miscellaneous.

The Electronic Transactions Law contains very broad enabling provisions that allow any legal requirements for signatures to meet by electronic signatures and contracts to be formed electronically. Some significant exceptions (including documents relating to title) are listed in that law.

The Electronic Transactions Law establishes the Central Body of Electronic Transactions to implement the legislation, comprising the minister for the Ministry of Communications and Information, Technology as the Chairman and the relevant ministries, governmental department and organizations and technicians as members. The legislation also establishes the Electronic Transactions Control Board for the day-to-day regulation of electronic signatures.

Apart from the Electronic Transactions Law, a new law "the Telecommunications Law " is enacted in 2013. The Telecommunications Law 2013 initiated by the Ministry of Communications and Information, Technology (former the Ministry of Communications, Posts and Telegraphs) was enacted.

The Myanmar Telegraph Act 1885 and The Myanmar Wireless Telegraphy Act 1934 were not inconformity with the current Myanmar telecommunications market. Myanmar government prepared new law which could replace two old laws. Now Myanmar ICT law 
consist of 3 pillars; the Computer Science Development Law 1966, Electronic Transactions Law 2004, Telecommunications Law 2013[4].

\subsection{Significance of ICT Legal Framework}

Establishment of ICT legal framework is very important. Myanmar has searched ICT laws from other countries for the advancement of ICT legal framework in Myanmar. It is a major premise for ICT infrastructure, ICT industry, Human Resources Development, eGovernment, e-Commerce, Informatization sectors.

ICT laws however have complicated system. It is difficult to digest unless one understands the communications technology and innovations. Because ICT laws have the common character all over the world, global developments and international initiatives have to be taken into account. In Myanmar, the bill of the ICT laws was doing well under supervision of e-Legal Infrastructure Working Committee. The committee had studied the UNCITRAL Model Law, cyber laws of ASEAN members and other countries including South Korea. The in-depth study on these foreign cases had an effect on the Myanmar ICT Legal System and thus the Electronic Transactions Law was promulgated on 30th April 2004.

\section{Myanmar Telecommunications Market Review}

\subsection{Telecommunications Infrastructure}

Recently environments of Myanmar telecommunications market change dramatically, especially with the starting of Telenor and Ooredoo business. The Ministry of Communications and Information Technology (MCIT) signed an agreement with Sumitomo Corporation and NTT Communications Corporation, Japan to develop the country's Emergency Communications Networks Improvement Plan in May 2013. The Japan International Cooperation Agency provided the 1.7 billion Yen as Official Development Assistance Grant. It funded the strengthening of connections between Yangon, Nay Pyi Taw and Mandalay[5].

Primary features of the communications infrastructure include the following:

- High speed, high capacity core optical transmission network capable of transmitting 30Gbps between Yangon, Nay Pyi Taw and Mandalay

- LTE communications, fixed-line telephones and optical transmission networks capable of $10 \mathrm{Gbps}$ Internet transmissions within each city.

- Installation of international internet connection points in Yangon and Nay Pyi Taw.

- Introduction of state-of-the art technologies within the communications bureau that include Virtualized Evolved Packet Core, virtual mobile network solutions and DW7000 optical transmission equipment.

- Infrastructure that supports the simultaneous use of services for approximately 40,000 LTE subscribers, about 1.5 million fixed-line telephone subscribers and about 1 million internet subscribers.

- Introduction of new backbone routers for internet backbone duplication in Yangon, Nay Pyi Taw and Mandalay. 


\subsection{Penetration of the Internet}

There were only 4 people who could access internet in 1988, but by December 2013 that had risen to 500,000 people who correspond roughly $1 \%$ of the population. This is one of the lowest internet penetration rates in the world. The majority of internet access is through internet enabled mobile devices or through public access centers like internet cafe. The barriers to internet penetration are currently the high tariff rates, high installation set up fees, and the limited infrastructure. It is expected that the internet penetration will rapidly increase once the new telecommunications licenses' services are established[6].

MPT and Yatanarpon Teleport Company (YTC) are licensed to provide broadband services. It is expected that Internet Service Providers (ISPs) will increase in the near future, as the Myanmar government will issue more licenses. At the end of 2013, MPT has $30 \%$ of market share, followed by YTC with $30 \%$, and RedLink with $23 \%$. The existing ISPs will also face competition from Telenor and Ooredoo.

ADSL (Asymmetric Digital Subscriber Line) service is provided through MPT and YPT. It is designed to deliver broadband services to end users over existing copper telephone wire infrastructures. Users therefore need to have a fixed-line. The downstream speed is between 128 and $384 \mathrm{Kbps}$.

\subsection{Telephones}

The telephone density was $0.7 \%$ in 2003 . Telephone lines are not widespread especially in the rural area. However, telecommunication facilities are gradually getting installed in urban area such as Yangon and Mandalay. Many people in these cities also use cellular phones.

Telephone density means the sum of subscribers to telephone and mobile phone per 1,000 people. In Myanmar, only 9.8million access to a telephone of 62 million populations in 2013. Yangon and Nay Pyi Taw have the highest penetration rates, while most rural areas don't have a fixed line service due to the lack of inter-city or interregional transmission facilities. Now Myanmar government try to increase the rate of people who are having telephones to between $75 \%$ $80 \%$ by 2016 .

Relating to mobile telecommunications, there are 7 mobile systems; D-AMP, GSM, CDMA-450MHz, WCDMA, CDMA-800MHz WLL and McWiLL. Mobile penetration has been largely dependent on availability and cost of SIM cards. In 2009 2010, a postpaid SIM card costed about 2,000\$. In 2012, MPT cut down the price of SIM card from 500\% to 250\$. MECTel which owned by Myanmar Economic Corporation and MPT distributed 350,000 cards all areas of Myanmar. In April 2013, new SIM cards for CDMA and WCDMA network system would be sold at a cost of only $2 \$$.

The telephone density was $0.7 \%$ in 2003. Telephone lines are not widespread especially in the rural area. However, telecommunication facilities are gradually getting installed in urban area such as Yangon and Mandalay. Many people in these cities also use cellular phones.

Telephone density means the sum of subscribers to telephone and mobile phone per 1,000 people. In Myanmar, only 9.8million access to a telephone of 62 million populations in 2013. Yangon and Nay Pyi Taw have the highest penetration rates, while most rural areas don't have a fixed line service due to the lack of inter-city or interregional transmission facilities. Now Myanmar government try to increase the rate of people who are having telephones to between $75 \% \sim 80 \%$ by 2016 .

Relating to mobile telecommunications, there are 7 mobile systems; D-AMP, GSM, CDMA-450MHz, WCDMA, CDMA-800MHz WLL and McWiLL. Mobile penetration has been largely dependent on availability and cost of SIM cards. In 2009 2010, a postpaid SIM card costed about 2,000\$. In 2012, MPT cut down the price of SIM card from 500\% to 250\$. MECTel which owned by Myanmar Economic Corporation and MPT 
distributed 350,000 cards all areas of Myanmar. In April 2013, new SIM cards for CDMA and WCDMA network system would be sold at a cost of only $2 \$$.

The telephone density was $0.7 \%$ in 2003. Telephone lines are not widespread especially in the rural area. However, telecommunication facilities are gradually getting installed in urban area such as Yangon and Mandalay. Many people in these cities also use cellular phones.

Telephone density means the sum of subscribers to telephone and mobile phone per 1,000 people. In Myanmar, only 9.8million access to a telephone of 62 million populations in 2013. Yangon and Nay Pyi Taw have the highest penetration rates, while most rural areas don't have a fixed line service due to the lack of inter-city or interregional transmission facilities. Now Myanmar government try to increase the rate of people who are having telephones to between $75 \%$ 80\% by 2016 .

Relating to mobile telecommunications, there are 7 mobile systems; D-AMP, GSM, CDMA-450MHz, WCDMA, CDMA-800MHz WLL and McWiLL. Mobile penetration has been largely dependent on availability and cost of SIM cards. In 2009 2010, a postpaid SIM card costed about 2,000\$. In 2012, MPT cut down the price of SIM card from 500\% to 250\$. MECTel which owned by Myanmar Economic Corporation and MPT distributed 350,000 cards all areas of Myanmar. In April 2013, new SIM cards for CDMA and WCDMA network system would be sold at a cost of only $2 \$$.

\subsection{Privatization in Telecommunications Sector}

One of a barrier to mobile phone use has been the lack of telecommunications infrastructure. Telenor and Ooredoo won the operating licenses in June 2013 successfully, and start their business in January 2014. In the beginning of 2014, the Myanmar telecommunications sector was privatised with 4 international and local companies. They have committed to connecting $90 \%$ of the country over the next 5 years. And they have been set a target to reach $80 \%$ of the population by 2016 .

\section{Telecommunications Law Issues}

\subsection{The Course for Legislation of the Telecommunications Law}

Directions of the telecommunications law can be summarized as follows: (1) introducing competition by telecommunications law, (2) reducing uncertainty in telecommunications policy executing, and (3) updating ICT law package into a harmonized model.

Competition is the best way to spur innovation and the development of new services. A competitive market place is the most efficient way to lower prices and increase consumer welfare. Myanmar, however, is the beginning stage of ICT development. Achieving free and fair competition requires strict parity of marketplace opportunities and responsibilities on the part of incumbent telecommunications service providers as well as new entrants into the telecommunications market place, provided that any responsibilities placed on providers should be the minimum required to advance a clearly defined public policy goal. Workable competition in telecommunications markets will ensure customers the widest possible choice of service and equipment, tailored individual desires and needs, and at prices they are willing to pay.

Government should establish clear statutory guidelines, standards, and timeframes to facilitate more effective competition and, by so doing, will reduce business and customer uncertainty, lessen regulatory processes, litigation, and thus encourage the business community to focus more on competing in the domestic and international communications marketplace.

Updating ICT legal framework is needed to cover areas which are missing or needed amending. Myanmar ICT legal framework is seemed to be weak or missing. The weakest 
point is that there is no competition in telecommunications market and no detailed plan for telecommunications network (ICT industry infrastructure) building[7 ].

The scope of services covered by the law is broad as like bellowing;

- The provision of operation of infrastructure or network facilities.

- The provision of service for transmission and reception of information.

- The provision of services by the way of transmitting and receiving.

\subsection{Licenses System by the Telecommunications Law}

There are three types of licenses, notably: the Network Facilities Service which is subdivided into Individual and Class licenses - NFS-I and NFS-C), the Network Service (NS) and the Application Service (AS) licenses.

The Network Facilities Service License (Individual) (hereafter referred to as the NFS(I) License) is at the highest hierarchical level and permits Licensees holding this authorization to engage in all activities authorized by the NFS(I) License, Network Facilities (Class) License, Network Service License and Application Service License. NFS(I) Licensees shall not be required to apply for or register for any other Licenses issued under this Licensing Framework.

The Network Facilities Service (Class) License (hereafter referred to as the NFS(C) License) permits Licensees to engage in only those activities authorized by the NFS(C) License unless the Licensee holding this authorization also applies for and obtains another Telecommunications Service License. An NFS(C) Licensee may apply for and obtain a Network Service or Application Service License, and would subsequently hold a maximum of two (2) Telecommunications Service Licenses.

The Network Service License (hereafter referred to as the NS License) permits Licensees to engage in all activities authorized by the NS License and the Application Service License, but does not permit such Licensees to engage in activities authorized by the NFS(I) License or NFS(C) License. An NS Licensee may apply for and obtain an NFS(C) License, and would subsequently hold a maximum of two (2) Telecommunications Service Licenses. If an NS Licensee applies for and obtains an NFS(I) License, then the NFS(I) License would replace the NS License.

The Application Service License (hereafter referred to as the AS License) permits Licensees to engage in only those activities authorized by the AS License. An AS Licensee may apply for and obtain an NFS(C) License, and would subsequently hold a maximum of two (2) Telecommunications Service Licenses.

Actually, it is better to count the NFS-I and NFS-C as if they were separate altogether, because an NSF-C license does not allow a licensee to provide telecommunications services, but only to construct and hold passive infrastructure and lease it to an operator.

Besides these licenses, other authorizations also exist under the Proposed Licensing Rules, such as the "Equipment License", approval for the use of spectrum which is not included in the NFS-I or the NS license and authorizations for numbering.

The Proposed Licensing Rules include the four licenses, and the processes for obtaining the licenses. More precisely, the application process for NFS-I and NS licenses is more complicated than that for AS and NFS-C licenses. For AS and NFS-C licenses, it appears that only a registration is required.

The evaluation process periods are similar to the Myanmar Investment Commission (MIC) evaluation periods up to 90 days. The MIC may not accept applications and will refer to the MCIT for the NFS-I and the NS licenses.

In addition, the telecommunications law applies to both local and foreign licenses. There are however slightly different rules applying to each.

- Local and foreign applicants need to apply for a telecommunications service licence with the Telecommunications Department of MCIT

- The Telecommunications Department will review the application and submit its recommendation to MCIT (for local applicant) or Union Government of Myanmar 
(for foreign applicant)

- Upon approval, the Telecommunications Department will issue a service licence with a validity period of 5 to 20 years; subject to re-approval by MCIT upon reapplication

- Providing a telecommunications service without a licence can lead to imprisonment of up to 5 years and fine with no statutory limit.

MCIT and the telecommunications Department will enforce all telecommunications regulations. MCIT can set a licence fee, renewal fee, usage fee, service charge and technology fee[8].

\subsection{Interconnection Regulation}

The Proposed Interconnection and Access Rules impose an obligation upon operators to interconnect with other operators. Especially, the so-called market dominant operator, which would have to be the MPT initially, has an obligation to issue a Reference Interconnection Offer (RIO) with standard terms and conditions under which it is prepared to interconnect. The RIO must also be posted on the dominant operator's website. According to the Proposed Interconnection and Access Rules, quick negotiations and non-discriminatory treatment in the application of interconnection rates must be required.

Interconnections between service providers must be conducted on an equitable and non-discriminatory basis, and the technical standards and quality of connection should not be lower than that provided in the licensee's own network. The Telecommunications Department has the authority to set the rules and regulations. Any interconnection agreements between service providers must be approved by the Telecommunications Department[9].

Unlike an earlier draft of the Telecommunications Law, the enacted text does not explicitly state that fees for interconnection and access to infrastructure or services must be charged on a cost basis. The Proposed Interconnection and Access Rules chose that idea, but it has been watered down. Section 9 a) of the Proposed Interconnection and Access Rules now states that "rates for Interconnection services shall be cost-oriented and set to allow the Qualifying Licensee providing the service to recover its costs of providing the service together with a reasonable return on its capital employed". The term "reasonable return" is not further defined.

Proposed Rules for Telecommunications Sector Relating to Licensing, Access and Interconnection, Spectrum, Numbering, and Competition notes on the subject that "retail minus" and "cost based pricing" might alternatively be employed (Part III, par. 28). The retail minus method would certainly lead to an element of profit being introduced into the equation.

\subsection{Price Regulations and Competition Policy}

Price control mechanisms have been built in the Telecommunications Law. The Telecommunications Department is mandated to determine certain consumer protection standards that will apply to service licenses. The law requires that all licensees have to submit a schedule of tariffs which needs to be approved by MCIT. Any behaviors against free and fair competition in the telecommunications market are prohibited. As an entirely new competitive environment emerges in Myanmar, and as a wide range of network assets is being deployed, a number of new legal issues emerged. Competition and access concerns became central points of Myanmar telecommunications policy.

The PTD has put a lot of effort into creating a comprehensive set of rules to ensure that the market can develop in an open and competitive manner. Conduct and agreements that lessen competition may be challenged by the Regulator, and trigger penalties. For example, failing to provide interconnection, preemptively securing scarce facilities to 
prevent others from using them, or using different rates for services to licensees may be deemed anti-competitive. Agreements between licensees or between a licensee and a nonlicensee are prohibited insofar as the agreement has "the object or effect of significantly preventing, restricting or distorting competition in any relevant telecommunications market". There are far-reaching rules on having to provide interconnection and access to infrastructure to other licensees. In a market, where there is only one market-dominant operator, the new entrants need to make sure that the dominant operator does not pull the sheet too far to his own side. Therefore these rules mentioned above are actually necessary[10].

The problem is that that is passively over-regulation. Firstly, in terms of who is subject to the Competition Rules. Depending on the obligation, the Competition Rules extend to every licensee, not just to a dominant licensee. The definition of a dominant licensee is fact-based, but the PTD can deem anyone a dominant licensee who has a $30 \%$ market share of any relevant market. By Comparison, the competition rules of the WTO Reference Paper on Telecommunications Service applies only to "major suppliers", which mean suppliers who have the ability to materially affect the terms of participation (with regard to price and supply) in the relevant market for basic telecommunications services as a result of: (a) control over essential facilities; or (b) use of is position in the market (Definitions and Section 1.1). The EU Access Directive also imposes access obligations only to operators "with significant market power".

Secondly, licensees of all classes are held of the same Competition Rules. Extensive regulation may very well be appropriate for operators, but all of other licensees such as tower companies, directory providers and internet service providers must abide by the same rules. Particularly it is difficult for small and medium sized enterprises in Myanmar to obey the Competition Rules and perhaps costly to assure compliance. The definition of "telecommunications services" in the Rules encompasses all activity which is subject to any of the different licenses, thus including infrastructure providers and providers of value-added services. In WTO law, the GATS Annex on Telecommunications defines the scope much narrower, limiting "telecommunications" to "transmission and reception of signals by electromagnetic means" (Section3 (a) GATS Annex on Telecommunications).

Finally, sometimes even non-licensees can be applied in the Competition Rules. Any non-licensee who is a party of a transaction involving a licensee could be subject to penalties if the transaction is determined to be anti-competitive. Building owners, vendors or other non-licensee businesses player who exclusively interact with one or several licensees would have to interpret their business in the context of the Competition Rules.

\section{Conclusion}

Competition policy is an essence of telecommunications law. A policy framework to establish, foster and maintain competition is critical to consumers benefit improvement. Liberalization is also key function of telecommunications law. It is recommended that the government should separate the operational activities from the policy and regulatory activities in the telecommunications sector[11]. Myanmar may not avoid the worldwide trend of liberalization of telecommunication business. When it is inevitable to face the change of monopoly telecommunication market structure, it should have a blue print for the change of progressive regulation policy suitable for ICT environment in Myanmar.

With respect to the telecommunications law and policy, this article introduces how to develop a roadmap and related action plan. First of all, the Myanmar government should set up a desired needed to accomplish national economic development in a quick manner by building infrastructure and nurturing its telecommunication market. It is necessary to introduce level of competition in according to specific time schedules. Liberalization is urgently competition into the telecommunication market as soon as possible. The adoption of liberalization and privatization is also needed gradually. Higher quality 
telecommunication service with lower prices can be provided to end-users in Myanmar through these liberalization and privatization efforts. It also contributes to Myanmar's economic development by developing the tele-communication industry.

In the reference to privatization in the telecommunications sector, South Korea could be a role model for Myanmar. In the case of KT (Korea Telecom) privatization, the Ministry of Information \& Communications (MIC) implemented three stages in order: (1) separation and specialization policy (2) partial privatization and liberalization policy, and (3) full privatization and liberalization policy. MCIT can approach in the way like same way alike the KT case, in privatizing a separated telecommunication company after initiating a separation and specialization policy.

It is necessary for the Myanmar government to initially take revolutionary measures such as separating business functions which are providing telecommunication services to end-users and regulatory functions which are controlled by the government. Vietnam Posts and Telecommunications Group (VNPT), Vietnam is an example of the separation of business functions. To liberalization and privatization of the telecommunication industry in Myanmar, firstly it has to pass through a "separation and specialization era" which is a transition period based on the continuous non-government monopoly of each telecommunication service market.

Next stage is so-called the "managed competition era" between oligopolists. It is the transitional stage towards the goal of workable competition in the telecommunication market. By this "managed competition era", it is possible to create an independent organization of government investment which is separate from the existing government agency and to make a private corporation which can do same businesses.

The last stage is the "free and fair competition era." It can accomplish, when MCIT maintains workable competition in each telecommunication service market. During this period, MCIT will permit a number of new network service providers for the purpose of opening up a new telecommunication service market.

\section{References}

[1] Nyo Nyo Thinn, "The legal system in Myanmar and the foreign legal assistance", Keio Law Journal, No.5, (2006), pp. 389-396.

[2] Myanmar Computer Industry Association, "Myanmar Information \& Communication Technology Directory 2014-15", Toppan Leefung Printing Co., LTD, Yangon, (2014) .

[3] Tun Shin, "Why Invest In Myanmar? and other Notable Legal Articles", Wisdom House, Yangon, (2013).

[4] Maw Maw Aye, "VIII. ICT Legal Framework", Edited KOICA, Myanmar ICT Development Master Plan Project Final Report, (2005), pp. 310-350

[5] Myanmar Computer Industry Association, "Myanmar Information \& Communication Technology Directory 2014-15", Toppan Leefung Printing Co., LTD, Yangon, (2014) .

[6] HTML Standard, http://www.myanmaritdirectory.com/ (2015).

[7] Seong-Min Cha, "Myanmar Telecommunications Market \& Law Issues", Asia-pacific Proceedings of Applied Science and Engineering for Better Human Life, Vol.6, (2016), pp. 17-20.

[8] VDB/Loi, “TELECOM MYANMAR UPDATE”, (2014).

[9] Kee-Yung Nam, Maria Rowena Cham, and Paulo Rodelio Halili, "DEVELOPING MYANMAR'S INFORMATION AND COMMUNICATION TECHNOLOGY SECTOR TOWARD INCLUSIVE GROWTH" ADB ECONOMICS WORKING PAPER SERIES, No. 462, Asian Development Bank, (2015).

[10] S.M. Cha: "Formation and Issues of Myanmar Telecommunications Law," Journal of Science \& Technology Law, Vol.21, No.2, (2015), pp. 185-186.

[11] HTML Standard, http://www.ictregulationtoolkit.org/en/home (2016). 


\section{Author}

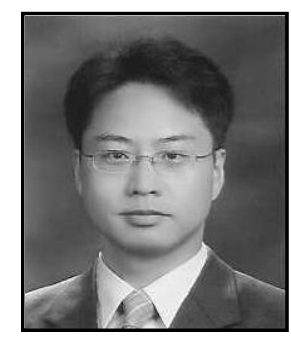

Seong-Min Cha, is a professor of the college of Law, Han-Nam University. He is also an ODA consultant at the KOICA. He had worked as a senior researcher of the Electronics Communications Research Institute (ETRI), as well as a director of several academic societies. He has maintained a keen interest in economic law, IT law, and public policy, serving in positions such as a legal advisor to the IT Infrastructure Planning Program of Myanmar to design Myanmar's ICT legal master plan. 